\title{
Ginsenoside compound $K$, not Rb1, possesses potential chemopreventive activities in human colorectal cancer
}

\author{
CHONG-ZHI WANG $^{1}$, GUANG-JIAN DU ${ }^{1}$, ZHIYU ZHANG ${ }^{1}$, XIAO-DONG WEN ${ }^{1}$, TYLER CALWAY ${ }^{1}$, \\ ZHONG ZHEN ${ }^{1}$, MARK W. MUSCH ${ }^{2}$, MARC BISSONNETTE ${ }^{2}$, EUGENE B. CHANG ${ }^{2}$ and CHUN-SU YUAN ${ }^{1,3}$ \\ ${ }^{1}$ Tang Center for Herbal Medicine Research, and Department of Anesthesia and Critical Care, ${ }^{2}$ Department of Medicine, \\ ${ }^{3}$ Committee on Clinical Pharmacology and Pharmacogenomics, University of Chicago, Chicago, IL 60637, USA
}

Received October 11, 2011; Accepted November 21, 2011

DOI: 10.3892/ijo.2012.1399

\begin{abstract}
Ginsenoside compound $\mathrm{K}(\mathrm{C}-\mathrm{K})$ is an intestinal microbiota metabolite of ginsenoside $\mathrm{Rb1}$, a major constituent in American ginseng. However, previous ginseng anti-cancer observations were largely focused on ginseng parent compounds but not metabolites, and anti-colorectal cancer studies on $\mathrm{C}-\mathrm{K}$ were limited. This study investigated the anti-proliferative effects of $\mathrm{C}-\mathrm{K}$ when compared to those of $\mathrm{Rb} 1$, and the related mechanisms of action, in HCT-116 and SW-480 colorectal cancer cells. The effects of $\mathrm{Rb} 1$ and $\mathrm{C}-\mathrm{K}$ on the proliferation of HCT-116 and SW-480 human colorectal cancer cells were compared using an MTS assay. Cell cycle and cell apoptosis were assayed using flow cytometry. Enzymatic activities of caspases were determined by colorimetric assay, and interactions of $\mathrm{C}-\mathrm{K}$ and caspases were explored by docking analysis. C-K showed significant anti-proliferative effects in HCT-116 and SW-480 cells at concentrations of $30-50 \mu \mathrm{M}$. At the same concentrations, $\mathrm{Rb} 1$ did not show any effects, while $\mathrm{C}-\mathrm{K}$ arrested the cells in the G1 phase, and significantly induced cell apoptosis. Compared to HCT-116 (p53 wild-type), the p53 mutant cell line SW-480 was more sensitive to $\mathrm{C}-\mathrm{K}$ as assessed by cell cycle regulation and apoptosis induction. $\mathrm{C}-\mathrm{K}$ activated expression of caspases 8 and 9, consistent with docking analysis. The docking data suggested that C-K forms hydrogen bonds with Lys253, Thr904 and Gly362 in caspase 8, and with Thr62, Ser63 and Arg207 in caspase 9. C-K, but not its parent ginsenoside Rb1, showed significant anti-proliferative and pro-apoptotic effects in human colorectal cancer cells. These results suggest that $\mathrm{C}-\mathrm{K}$ could be a potentially effective anti-colorectal cancer agent.
\end{abstract}

\section{Introduction}

Ginseng root has been used for centuries in Oriental medicine as a panacea that promotes longevity (1). A number of investi-

Correspondence to: Dr Chun-Su Yuan, Department of Anesthesia and Critical Care, University of Chicago, 5841 South Maryland Ave., MC 4028, Chicago, IL 60637, USA

E-mail: cyuan@dacc.uchicago.edu

Key words: ginsenoside Rb1, compound K, chemoprevention, colorectal cancer, apoptosis, cell cycle, caspases, docking analysis gations, including cancer studies, have demonstrated beneficial effects of Asian ginseng (Panax ginseng C.A. Meyer) (2,3). As far back as 1971, Asian ginseng and its chemical constituents were tested for their inhibitory effect on human cancers (4). Subsequently, Yun and Choi reported a case-control epidemiological study on over a thousand Korean subjects, demonstrating that long-term Asian ginseng consumption was associated with a decreased risk for many different cancers (5). Their study also suggested that ginseng has a non-organ specific preventive effect against different cancers $(5,6)$. The effects of ginseng on colon cancer have also been reported (7).

American ginseng (Panax quinquefolius L.) is one of the most commonly used herbal medicines in the U.S. Many reports suggested that American ginseng, similar to Asian ginseng, reduces stress and enhances immune function against chronic diseases $(8,9)$. American ginseng extracts have been shown to inhibit the growth of breast cancer cells (10). We observed that the extract enhanced the anti-proliferative effect of cisplatin on human breast cancer cells, while it possessed its own anti-cancer activity (11). Recently, we demonstrated the chemopreventive effects of ginseng extract and its components on colorectal cancer cells and tumor xenografts $(12,13)$. Interestingly, during our studies, we did not observe significant anti-colorectal cancer effects of ginsenoside Rb1, a major component of American ginseng and Asian ginseng.

Like many other herbal medicines, the route of administration of American ginseng is nearly always oral. When the ginseng is ingested orally, its bioavailability is low due to incomplete parent compound absorption and conversion to metabolites. In the gut, the main metabolic pathways include deglycosylation reactions of ginseng saponins, including ginsenoside Rb1, by intestinal microbiota via stepwise cleavage of the sugar moieties (14-16).

Previous studies suggested that after ginseng ingestion, Rb1 was converted in the gut to compound $\mathrm{K}$ (C-K) (Fig. 1), and that the latter was a major metabolite absorbed into the systemic circulation $(14,17)$. As a parent compound, it appeared that Rb1 itself did not have obvious anti-cancer effects. However, C-K was shown to have remarkable anti-proliferative effects in HL-60 leukemia cells and HT-29 colorectal cancer cells $(18,19)$. Nevertheless, comparison studies of $\mathrm{C}-\mathrm{K}$ with $\mathrm{Rb}$ on a panel of human colorectal cancer cell lines have not been reported. The current study examined the anti-proliferative effects of C-K 


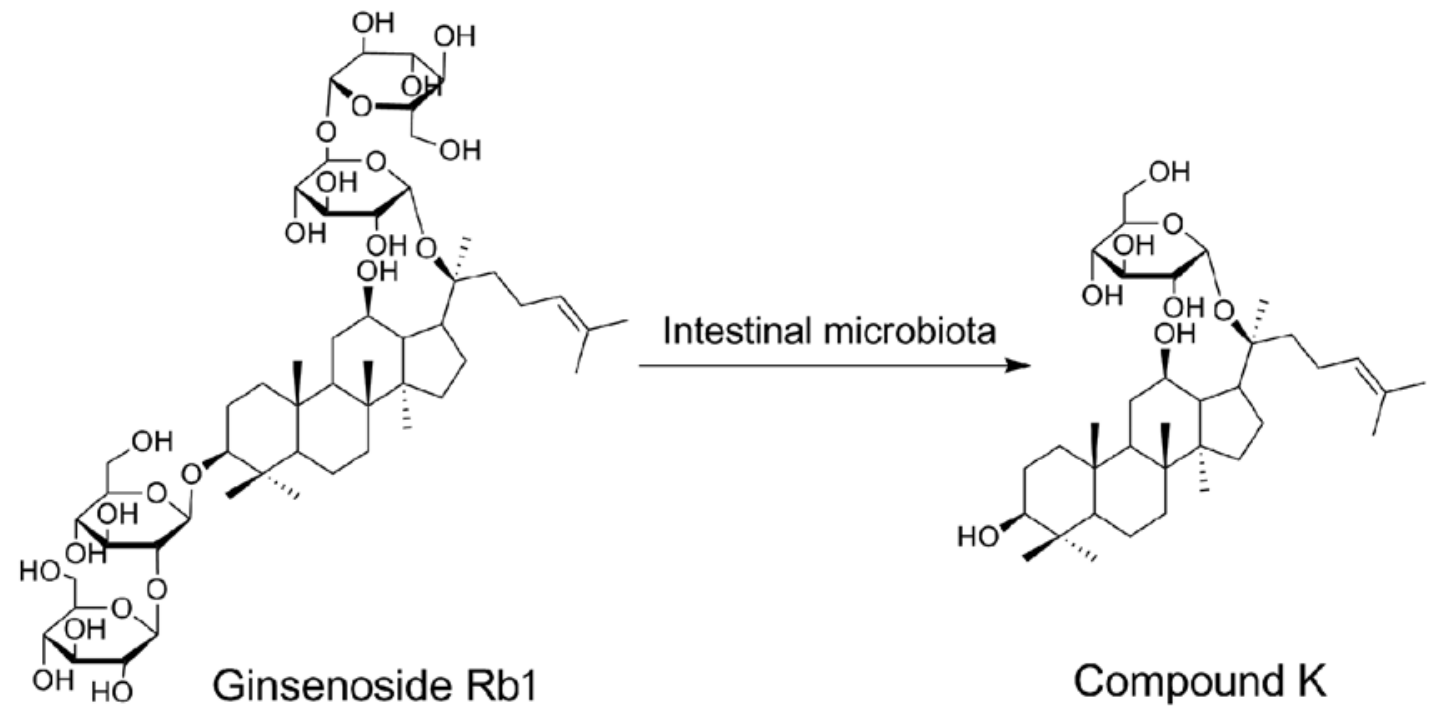

Figure 1. Chemical structures of ginsenoside Rb1 and compound K. C-K can be biotransformed from Rb1 by intestinal microbiota.

when compared to $\mathrm{Rb} 1$, and investigated potential mechanisms of action in HCT-116 and SW-480 colorectal cancer cells, which are wild-type and mutant p53 cell lines, respectively. These cell lines are prototypical of the two major forms of sporadic colon cancer: microsatellite and chromosomal unstable colon cancers, respectively.

\section{Materials and methods}

Reagents and materials. All cell culture plasticware were obtained from Falcon Labware (Franklin Lakes, NJ, USA) and Techno Plastic Products (Trasadingen, Switzerland). Trypsin, McCoy's 5A, Leibovitz's L-15 and RPMI-1640 media, and phosphate-buffered saline were obtained from Mediatech, Inc. (Herndon, VA, USA). Penicillin and streptomycin were obtained from Sigma-Aldrich (St. Louis, MO, USA). An MTS assay kit, CellTiter 96 Aqueous Solution Cell Proliferation Assay, was obtained from Promega (Madison, WI, USA). An Annexin V-FITC apoptosis detection kit was obtained from BD Biosciences (Rockville, MD, USA). PI/RNase staining buffer was obtained from BD Biosciences Pharmingen (San Diego, CA, USA). Caspase 3, 8, 9 kits were obtained from BioVison (Mountain View, CA, USA). Ginsenoside Rb1 was obtained from Indofine Chemical Company (Somerville, NJ, USA). Ginsenoside compound $\mathrm{K}$ was obtained from ChromaDex Inc. (Irvine, CA, USA).

Cell lines and cultures. The human colorectal cancer cell lines HCT-116 (McCoy's 5A) and SW480 (Leibovitz's L-15) were obtained from American Type Culture Collection (Manassas, VA, USA). The cells were grown in the indicated medium supplemented with $10 \% \mathrm{FBS}$ and $50 \mathrm{IU}$ penicillin/streptomycin in a humidified atmosphere with $5 \% \mathrm{CO}_{2}$ at $37^{\circ} \mathrm{C}$.

Young adult mouse colon (YAMC) cells are primary non-tumorigenic mouse colonocytes derived from an SV40 transgenic mouse (20). The YAMC cells were obtained from the Digestive Disease Research Core Center at the University of Chicago, and were grown in RPMI-1640 medium supple- mented with $5 \%$ neonatal calf serum, ITS $^{+}(6.25 \mathrm{mg} / \mathrm{ml}$ insulin, $6.25 \mathrm{mg} / \mathrm{ml}$ transferrin, $6.25 \mathrm{ng} / \mathrm{ml}$ selenous acid, $5.35 \mathrm{mg} / \mathrm{ml}$ linoleic acid, and $1.25 \mathrm{mg} / \mathrm{ml} \mathrm{BSA}$ ), $5 \mathrm{IU} / \mathrm{ml}$ murine IFN- $\gamma$, penicillin and streptomycin. The cells were cultured in a humidified atmosphere with $5 \% \mathrm{CO}_{2}$ at $33^{\circ} \mathrm{C}$.

Cell proliferation analysis by MTS. Ginsenoside Rb1 and compound $\mathrm{K}$ were dissolved in DMSO and were stored at $-20^{\circ} \mathrm{C}$ before use. Cells were seeded in 96-well plates $\left(1 \times 10^{4}\right.$ cells/ well). After $24 \mathrm{~h}$, indicated concentrations of drugs were added to the wells. The final concentration of DMSO was $1 \%$. Controls were exposed to culture medium containing $1 \%$ DMSO without drugs. All experiments were performed in triplicate and repeated 3 times. Following the indicated incubation period, cell proliferation was evaluated using an MTS assay according to the manufacturer's instructions. Briefly, the medium was replaced with $100 \mu \mathrm{l}$ of fresh medium and $20 \mu \mathrm{l}$ of MTS reagent (CellTiter 96 Aqueous Solution) in each well, and the plate was returned to the incubator for 1-2 h. A $60-\mu 1$ aliquot of medium from each well was transferred to an ELISA 96-well plate and its absorbance at $490 \mathrm{~nm}$ was recorded. Since 1\% DMSO did not influence the proliferation of the two cell lines, results were expressed as percent of control (DMSO vehicle set at 100\%).

Cell cycle and apoptosis analysis using flow cytometry. Cells were seeded in 24-well tissue culture plates. On the second day, the medium was changed and cells were treated with test compounds. Cells were incubated for $48 \mathrm{~h}$ before they were harvested. These cells were fixed gently with $80 \%$ ethanol in a freezer for $2 \mathrm{~h}$ and were then treated with $0.25 \%$ Triton $\mathrm{X}-100$ for $5 \mathrm{~min}$ on an ice bath. Cells were resuspended in $300 \mu \mathrm{l}$ of PBS containing $40 \mu \mathrm{g} / \mathrm{ml}$ propidium iodide (PI) and $0.1 \mathrm{mg} / \mathrm{ml}$ RNase. Then the cells were incubated in a dark room for $20 \mathrm{~min}$ at room temperature, and cell cycle analysis was performed using a FACScan flow cytometer (Becton-Dickinson, Mountain View, CA, USA) and FlowJo 7.1.0 software (Tree Star, Ashland, OR, USA). For each measurement, at least 10,000 cells were counted. 

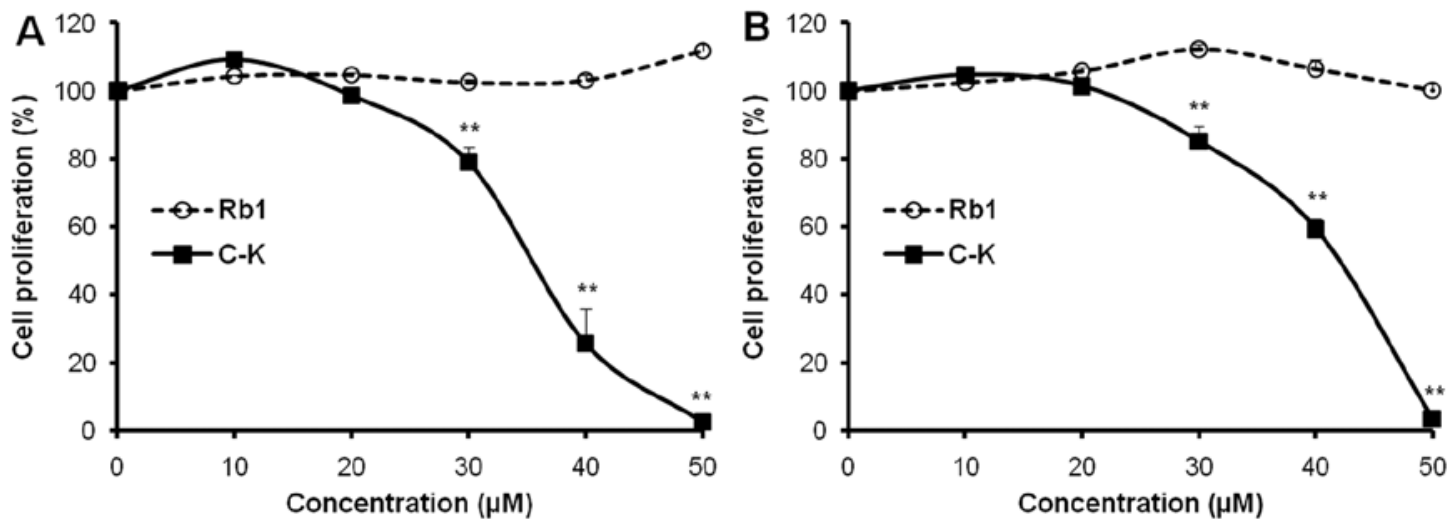

Figure 2. Effects of Rb1 and C-K on proliferation of human colorectal cancer cells. Cell lines of (A), HCT-116; and (B), SW-480 were employed to evaluate anti-proliferative effects of selected compounds. Cells were treated with 10-50 $\mu \mathrm{M}$ of Rb1 and C-K for $48 \mathrm{~h}$, and cell proliferation was assayed by MTS method. Results were normalized to each control in percentage and expressed as average \pm SD of three experiments (solvent vehicle set at $100 \%$, ${ }^{* *} \mathrm{P}<0.01$ vs. Rb1).

The apoptosis assay was performed by flow cytometry following a previously described procedure (21). Briefly, after treatment for $48 \mathrm{~h}$, cells floating in the medium were collected. The adherent cells were detached with trypsin. Then culture medium containing 10\% FBS (and floating cells) was added to inactivate trypsin. After being pipetted gently, the cells were centrifuged for $5 \mathrm{~min}$ at $1,500 \mathrm{~g}$. The supernatant was removed and cells were stained with Annexin V-fluorescein isothiocyanate (FITC) and PI according to the manufacturer's instructions. Untreated cells served as control. The cells were analyzed immediately after staining using flow cytometry. For each measurement, at least 20,000 cells were counted.

Caspases 3, 8 and 9 activities. SW-480 cells were seeded in 6-well tissue culture plates. After $24 \mathrm{~h}$, the medium was changed and $\mathrm{C}-\mathrm{K}$ was added. After treatment for $24 \mathrm{~h}$, cell lysates were collected. Expression levels of caspases 3, 8, and 9 were determined by colorimetric method according to the manufacturer's instructions. Briefly, cell lysates were diluted with $50 \mu 1$ of $2 \mathrm{X}$ reaction buffer (containing $10 \mathrm{mM}$ DTT) to protein concentration of $0.5 \mathrm{mg} / \mathrm{ml}$ in an ELISA 96-well plate. Then, $5 \mu$ l of colorimetric tetrapeptide substrate (DEVD-pNA for caspase 3, IETD-pNA for caspase 8 and LEHD-pNA for caspase 9) and cell lysate were added, and plate was incubated at $37^{\circ} \mathrm{C}$ for $24 \mathrm{~h}$. Absorbance was recorded at $405 \mathrm{~nm}$. The change in caspase activity was calculated as absorbance of $\mathrm{C}-\mathrm{K}$ treated cells/absorbance of untreated controls (22).

Receptor docking analysis. The possible binding modes of $\mathrm{C}-\mathrm{K}$ at the catalytic domains of human caspases 8 and 9 were predicted using the docking program Surflex-Dock (Tripos, St. Louis, MO, USA). The structure of C-K was generated (through Ligand model in Sybyl), and protein crystal structures were obtained (PDB code $2 \mathrm{C} 2 \mathrm{Z}$ for caspase 8 and $3 \mathrm{H} 0 \mathrm{E}$ for caspase 9). In preparation for docking analysis, the protein structures were prepared by adding hydrogen atoms and missing sidechain atoms and removing water molecules. Intermolecular interactions between the $\mathrm{C}-\mathrm{K}$ and caspases were analyzed, and the key pharmacophore in the ligand was identified $(23,24)$.
Statistical analysis. Data are presented as mean \pm standard error (SE). A one-way ANOVA was employed to determine statistical significance of results. In some cases, Student's t-test was used for comparing two groups. The level of statistical significance was set at $\mathrm{P}<0.05$.

\section{Results}

Anti-proliferative effects of $R b 1$ and $C-K$. We evaluated the anti-proliferative effects of the ginsenosides $\mathrm{Rb} 1$ and $\mathrm{C}-\mathrm{K}$ using two human colorectal cancer cell lines, HCT-116 and SW-480. As shown in Fig. 2, while 48-h treatment with Rb1 did not inhibit cancer cell growth, $\mathrm{C}-\mathrm{K}$ caused concentrationdependent growth suppression. At $30 \mu \mathrm{M}, \mathrm{C}-\mathrm{K}$ inhibited cancer cell growth by $15.5 \pm 4.5 \%$ in HCT-116 and $21.1 \pm 4.6 \%$ in SW- 480 cells, respectively (both $\mathrm{P}<0.01$ vs. Rb1). C-K at $50 \mu \mathrm{M}$ completely inhibited cell growth in both cancer cell lines.

In separate studies, we observed that both $\mathrm{Rb} 1$ and $\mathrm{C}-\mathrm{K}$, at concentrations as high as $50 \mu \mathrm{M}$, did not alter proliferation of the non-cancer YAMC cells.

Effects of Rb1 and C-K on cell cycle and apoptosis. To explore potential mechanisms by which $\mathrm{C}-\mathrm{K}$ inhibited cell growth, the cell cycle profile was assayed by flow cytometry. As shown in Fig. 3, compared to control, effects of C-K on the cell cycle profile were observed at concentrations as low as $20 \mu \mathrm{M}$. Treatment of HCT-116 cells with $40 \mu \mathrm{M} \mathrm{C}-\mathrm{K}$ for $48 \mathrm{~h}$ increased the percentage of cells in G1 phase to $63.4 \pm 1.2 \%$, compared to $49.7 \pm 1.7 \%$ in vehicle treated cells. Treatment of SW-480 cells with $40 \mu \mathrm{M} \mathrm{C}-\mathrm{K}$ for $48 \mathrm{~h}$ increased G1 phase cells to $78.6 \pm 2.5 \%$, compared to $53.1 \pm 3.0 \%$ in vehicle treated cells. Thus, in both cancer cell lines, C-K significantly increased the number of cancer cells in G1 phase. We also observed that Rb1 did not influence the cell cycle, suggesting that only the Rbl metabolite, $\mathrm{C}-\mathrm{K}$, inhibits $\mathrm{G} 1 \rightarrow \mathrm{S}$ transition in colorectal cancer cells.

The apoptotic effects of Rb1 and C-K were evaluated by flow cytometry after staining with Annexin V and PI. Annexin V can be detected in both early and late stages of apoptosis, whereas PI stains cells only in late apoptosis or necrosis. Early apoptotic cells were positive for Annexin V and negative for PI 

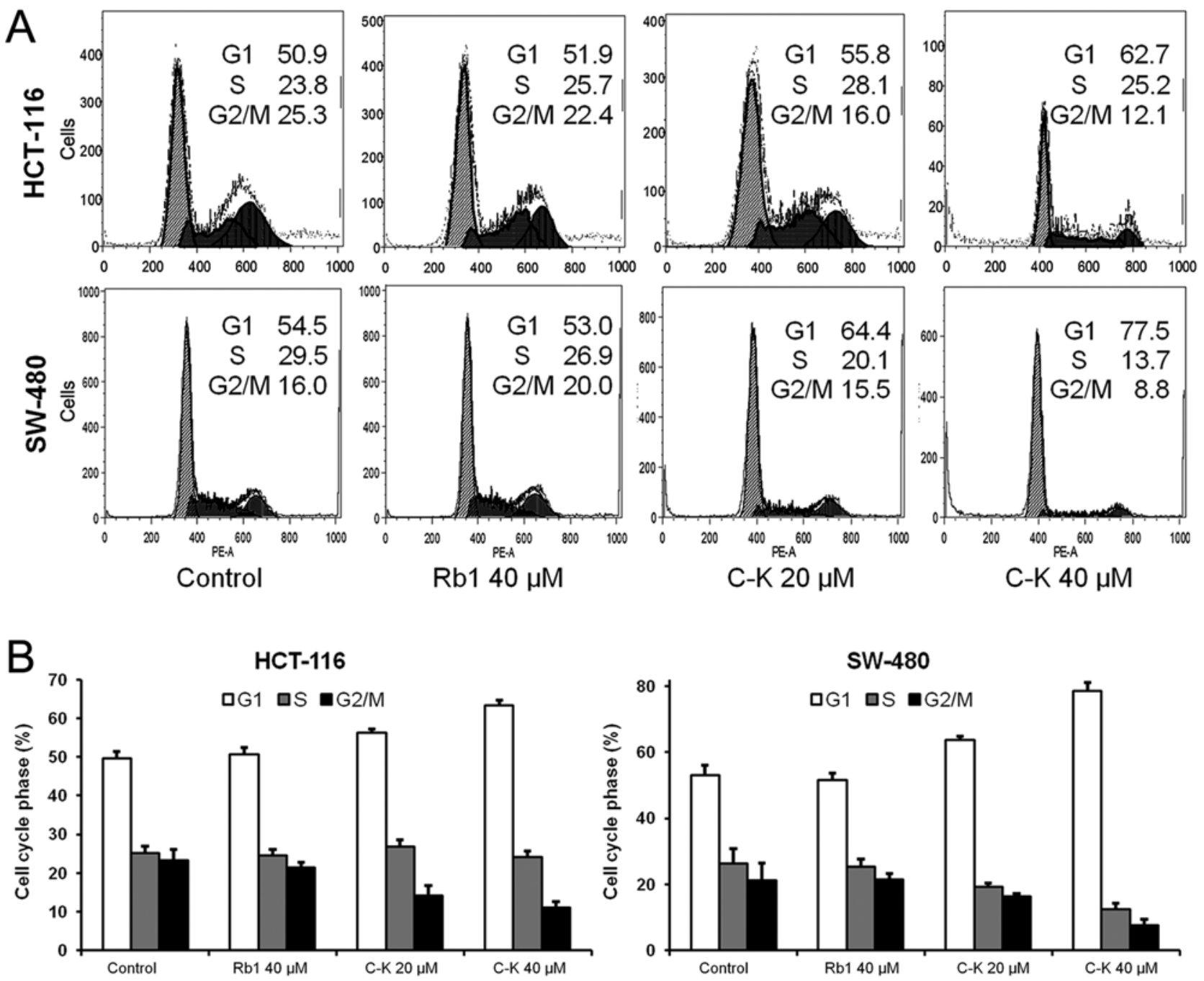

Figure 3. Cell cycle analysis of HCT-116 and SW-480 cells treated with Rb1 and C-K. HCT-116 and SW-480 cells were treated with 20 and $40 \mu \mathrm{M}$ of Rb1 or $\mathrm{C}-\mathrm{K}$ for $48 \mathrm{~h}$, then fixed in ethanol and stained with propidium iodide. DNA content was determined by flow cytometry. (A), Representative histograms of DNA content in each experimental group. The percentage of cells in G1, S and G2/M phases of the cell cycle is indicated. (B), Percentage of each cell cycle phase with various treatments or with control. Data are presented as the mean \pm standard error of triplicate experiments. C-K obviously induces cell cycle arrest at G1 phase, while $\mathrm{Rb} 1$ does not influence cell cycle profile compared to control.

(lower right quadrant); late apoptotic or necrotic cells stained for both Annexin V and PI (upper right quadrant). As shown in Fig. 4, following treatment with $50 \mu \mathrm{M}$ of C-K for $48 \mathrm{~h}$, the percentage of early and late apoptotic cells was $39.9 \pm 2.5 \%$ and $32.0 \pm 4.2 \%$ for HCT-116 cells (control: $4.0 \pm 1.3 \%$ and $1.4 \pm 0.3 \%$ ); and $56.2 \pm 3.0 \%$ and $23.6 \pm 2.4 \%$ for SW-480 cells (control: $3.5 \pm 0.5 \%$ and $1.8 \pm 0.2 \%$ ), respectively. In contrast, Rb1 at the same concentrations did not induce apoptosis. The data demonstrate that only $\mathrm{C}-\mathrm{K}$ significantly induces cell apoptosis.

Effects of Rbl and $C$ - $K$ on activities of caspases 3, 8 and 9. To further characterize the potential mechanism of C-K's anticancer activity, we assayed the activities of several caspases, since C-K increased colon cancer cell apoptosis. We measured caspase activity in SW-480 cells, since apoptotic induction by C-K was stronger in SW-480 compared to HCT-116 cells. As shown in Fig. 5, treatment of SW-480 cells with $40 \mu \mathrm{M} \mathrm{C-K}$ for $24 \mathrm{~h}$ up-regulated caspases 3,8 and 9 activities significantly. These activities were further enhanced with $50 \mu \mathrm{M}$ C-K, increasing caspases 3,8 , and 9 activities to $45.7 \pm 3.1 \%$,
$77.6 \pm 7.3 \%$, and $68.6 \pm 11.9 \%$, respectively (all $\mathrm{P}<0.01$ ), above vehicle treated cells.

Molecular modeling of caspases 8 and 9 and the predicted binding mode of $C$ - $K$. Since $\mathrm{C}-\mathrm{K}$ significantly increased caspases 8 and 9 activity, we asked if $\mathrm{C}-\mathrm{K}$ might physically interact with these caspases. To address this question, we examined C-K docking for human caspase 8 (PDB code: 2C2Z) and human caspase 9 (PDB code: $3 \mathrm{HOE}$ ). The Surflex-Dock program was used to predict the binding sites of $\mathrm{C}-\mathrm{K}$ to caspases 8 and 9. The energetically most favorable positions for $\mathrm{C}-\mathrm{K}$ interaction with these caspases are shown in Fig. 6. In silico modeling suggested that C-K forms hydrogen bonds with Lys253, Thr904 and Gly362 at the active site of caspase 8 through its hydroxyl groups (Fig. 6A), while it interacts with residues Thr62, Ser63 and Arg207 in caspase 9 through hydrogen bond interactions (Fig. 6B). In addition, $\mathrm{C}-\mathrm{K}$ is predicted to show significant binding affinity for caspase 8 (CScore 3.34) and caspase 9 (CScore 4.29), suggesting that C-K directly interacts with these caspases. 

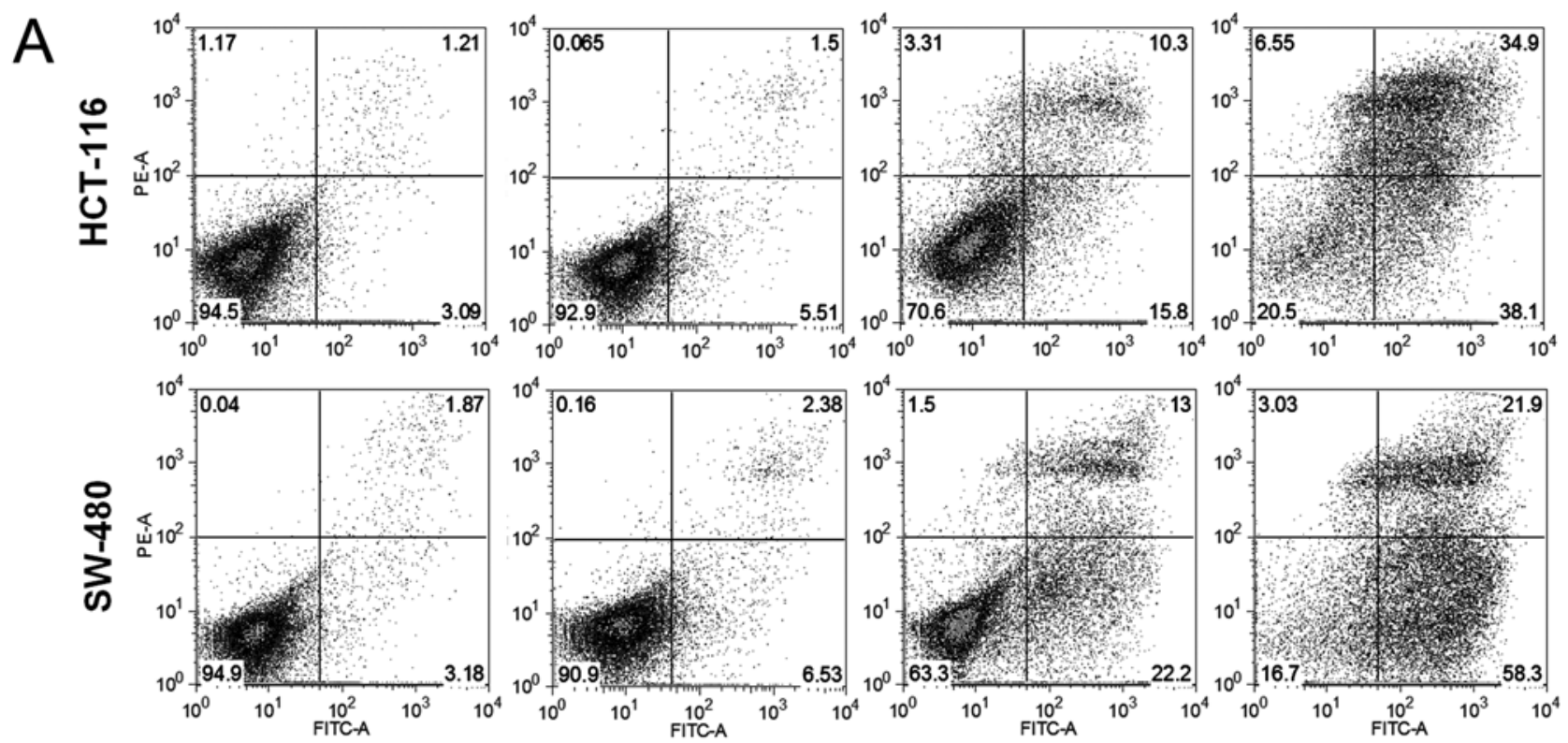

Control

$\mathrm{Rb} 150 \mu \mathrm{M}$

$\mathrm{C}-\mathrm{K} 30 \mu \mathrm{M}$

C-K $50 \mu \mathrm{M}$

B

HCT 116
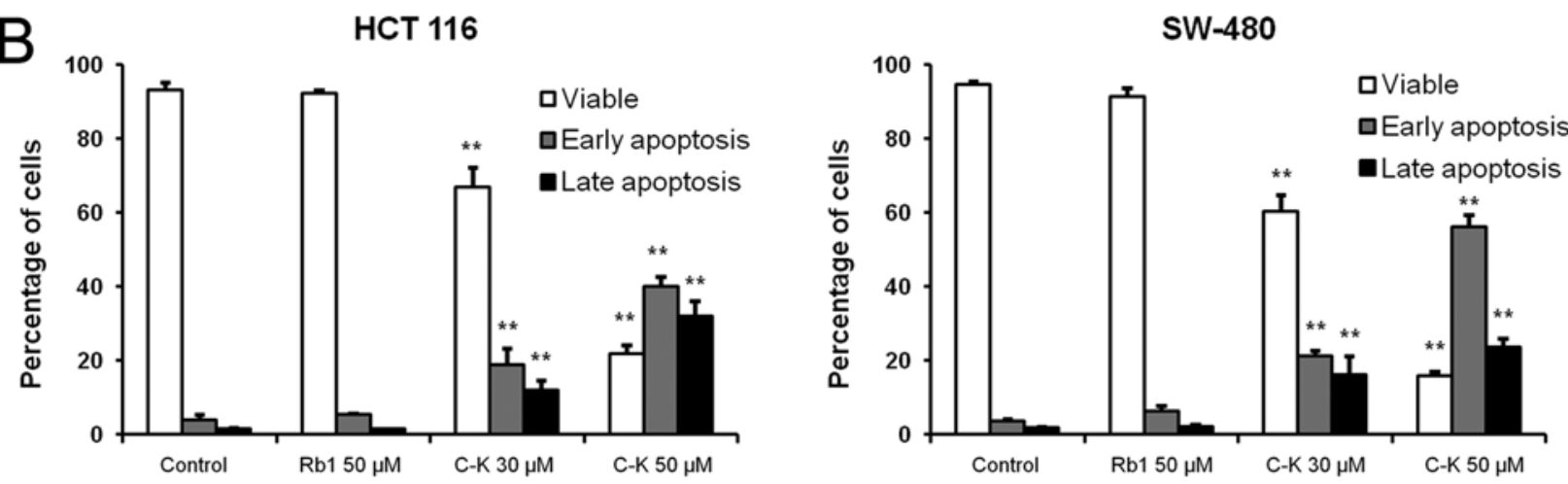

Figure 4. Apoptotic analysis of HCT-116 and SW-480 cells treated with Rb1 and C-K. HCT-116 and SW-480 cells were treated with 30 and $50 \mu \mathrm{M}$ of Rb1 or $\mathrm{C}-\mathrm{K}$ for $48 \mathrm{~h}$, then stained with Annexin V/PI, and the extent of apoptosis was determined by flow cytometry. (A), Representative scatter plots of PI (y-axis) vs. Annexin V (x-axis). (B), Percentage of viable, early apoptotic and late apoptotic cells. Data are presented as the mean \pm standard error of triplicate experiments. ${ }^{* *} \mathrm{P}<0.01$ vs. control. C-K induced cell apoptosis in a concentration-related manner. However, Rb1 did not induce cell apoptosis even at high concentrations.

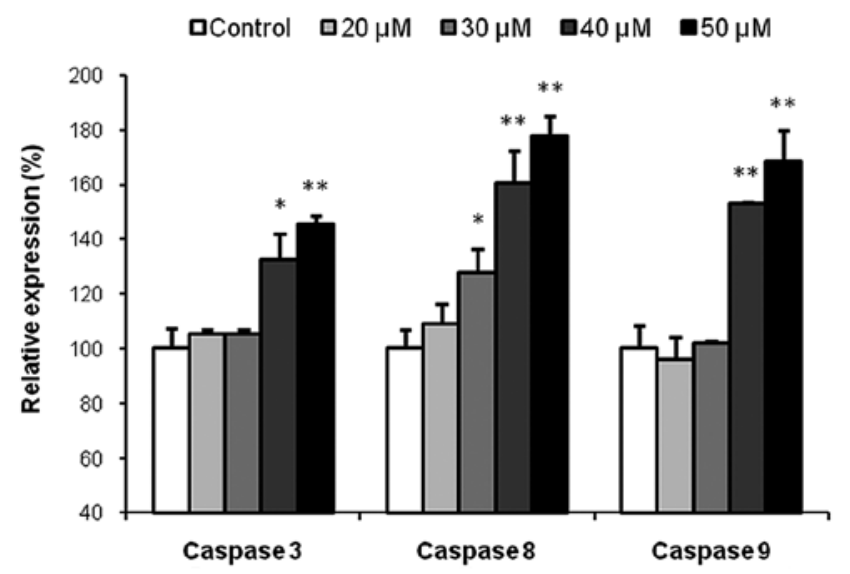

Figure 5. Effects of C-K on caspases 3,8, and 9 activities in SW-480 cells. After treatment with $20-50 \mu \mathrm{M}$ of C-K for $24 \mathrm{~h}$, cell lysates were prepared and enzymatic activities of caspases 3,8 , and 9 were measured by colorimetric assay. Results are normalized to each control in percentage and expressed as average $\pm \mathrm{SD}$ of three experiments $\left({ }^{*} \mathrm{P}<0.05,{ }^{* * *} \mathrm{P}<0.01\right.$ vs. control).

\section{Discussion}

Botanicals have provided parent structures for many of the current efficacious chemotherapeutic agents $(25,26)$. There needs to be a continued effort to tap this resource in order to discover active botanical components or metabolites with novel, potent, and distinct anti-cancer actions $(27,28)$. The identification of non-toxic chemoadjuvant treatments derived from herbal medicines remains a potentially very productive area of research to advance cancer chemoprevention.

Previous ginseng anti-cancer evaluations largely focused on the herb's parent compounds, i.e., the ginsenosides Rb1 and Rg1. Unfortunately these parent compounds have exhibited only limited anti-cancer activities. Our group observed that after steaming treatment, the chemical composition of ginseng was changed, and the anti-proliferative activity increased significantly. Steaming of American ginseng augmented ginsenoside $\mathrm{Rg} 3$ content and increased the ginseng's anti-proliferative potential. Although $\operatorname{Rg} 3$ exhibited more anti-proliferative activity 

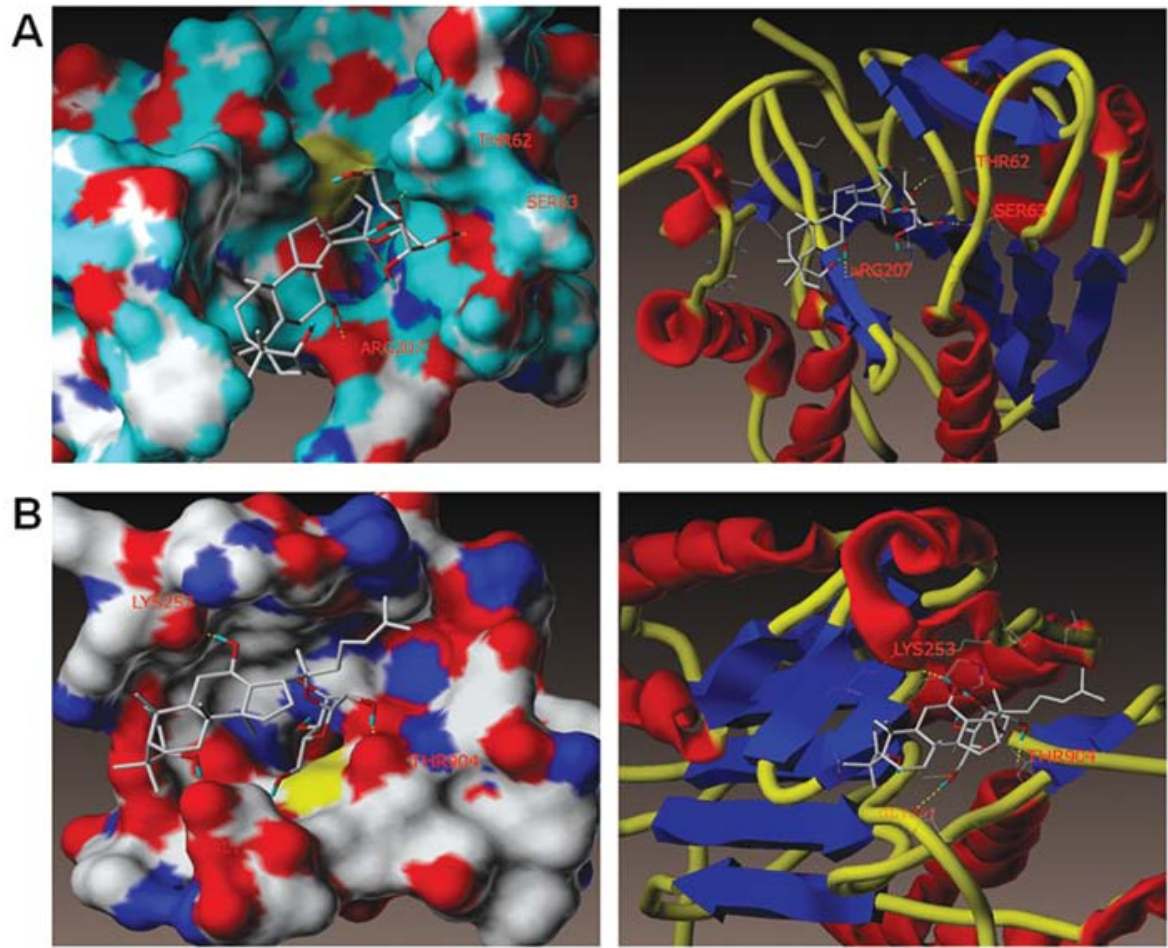

Figure 6. Three-dimensional docking model of $\mathrm{C}-\mathrm{K}$ at the binding site of human caspases 8 and 9 proteins. The possible binding modes of $\mathrm{C}$-K at the catalytic domains of caspases were predicted using the docking program Surflex-Dock. (A), C-K docked with caspase 8 through hydrogen bond interactions with residues Lys253, Thr904 and Gly362. (B), C-K docked with caspase 9 through hydrogen bond interactions with residues Thr62, Ser63 and Arg207. In (A) and (B), surface views are shown in the left panel, and stick-ribbon models shown in the right.

than its parent compound Rb1, its potency was still low, with an $\mathrm{IC}_{50}>100 \mu \mathrm{M}$ for colorectal cancer cells (29). Identification of more potent ginseng-derived anti-cancer compounds is challenging, as ginseng contains a diverse number of compounds and potential metabolites, and many appear to possess anticancer activities.

The common method of ginseng administration is the oral route. Orally administered ginsenosides are poorly absorbed, and some appear to require bacterial metabolism to be absorbed and biologically active (30). After ginseng ingestion, $\mathrm{C}-\mathrm{K}$ is a major metabolite reaching the systemic circulation $(14,17)$. In natural products research, many previous studies employed primarily reductionist approaches in screening compounds for bioactivity, and often only parent compounds were investigated. For ginseng studies, saponin bioavailability is an important issue linked to the compound's pharmacological effects, and it seems to have been overlooked.

In this study, we observed that the Rb1 metabolite $\mathrm{C}-\mathrm{K}$ possesses very significant anti-colorectal cancer activities compared to its parent compound $\mathrm{Rb} 1$. The $\mathrm{IC}_{50}$ for $\mathrm{C}-\mathrm{K}$ for inhibiting colon cancer cell proliferation and inducing apoptosis was 30-50 $\mu \mathrm{M}$, suggesting that its anti-proliferative effect is greater than that of $\mathrm{Rg} 3$, the compound derived from $\mathrm{Rb} 1$ by steaming treatment. We also observed significant anti-tumor activity of $\mathrm{C}-\mathrm{K}$, but not of Rb1, against cancer cells, but not against non-cancer cells. The microbe requirements for generation of gut microbiota-derived ginseng metabolites with respect to colorectal cancer chemoprevention will necessitate further study. Functional profiles of enteric microbiota with this activity can be studied in a number of ways, including estab- lishing 'humanized' enteric microbiota or transfer of defined microbiota using germ-free animal models $(31,32)$.

The mechanisms mediating the colon cancer chemopreventive effects of C-K are largely unknown. Because inhibition of cell cycle progression and induction of apoptosis are important mechanisms mediating the effects of many anti-cancer agents, in this study we evaluated the effects of $\mathrm{C}-\mathrm{K}$ on the cell cycle and apoptosis. C-K increased the fraction of colon cancer cells in the G1 phase, with SW480 cells showing greater G1 arrest. We also observed that C-K markedly induced colon cancer cell apoptosis, and that SW-480 cells again appeared to be more sensitive to $\mathrm{C}-\mathrm{K}$. Comparing $\mathrm{C}-\mathrm{K}$ effects on cell cycle and apoptosis, we showed that induction of apoptosis appeared to be greater than cell cycle slowing. This result suggests that the cancer cell growth inhibitory effect of $\mathrm{C}-\mathrm{K}$ was predominantly mediated by induction of apoptosis.

The two cell lines used in this study have varied p53 expression. HCT-116 is p53 wild-type, while SW-480 cells contain a p53 mutation. Cancer cells with p53 mutations are resistant to many chemotherapeutic agents. Interestingly, we observed that $\mathrm{C}-\mathrm{K}$ caused greater apoptosis induction abilities in a p53 mutant cell line (SW-480) than in a p53 wild-type line (HCT-116), suggesting that $\mathrm{C}-\mathrm{K}$ might prove useful in p53-mutated colon cancers.

To further explore the mechanism mediating C-K-induced enhanced apoptosis, we assayed the activities of caspases 3, 8 and 9. Since our flow cytometry experiments showed that the apoptotic effects of C-K were greater in SW-480 than HCT-116 cells, we examined SW-480 cells for caspase activity. At concentrations of 40 and $50 \mu \mathrm{M}, \mathrm{C}-\mathrm{K}$ significantly up-regulated 
the activities of these caspases, especially caspases 8 and 9. Our docking analysis further suggested interaction sites between $\mathrm{C}-\mathrm{K}$ and caspases 8 and 9. These caspases are situated at critical points in apoptotic pathways, and our studies suggest that C-K may enhance apoptosis by direct physical interactions with these enzymes.

In summary, we have demonstrated that $\mathrm{C}-\mathrm{K}$ exerts potent anti-proliferative and pro-apoptotic effects in colon cancer cells. This compound requires biotransformation of ginseng by bacteria, revealing a potentially important role for bacteria in mediating the chemopreventive effects of naturally occurring substances. Future studies to determine the pathways that mediate C-K-induced G1 cell cycle slowing and caspase activation are warranted. Investigation of the colonic microbiome requirements and elucidation of potential differences in human hosts (e.g., ethic differences) with respect to $\mathrm{C}-\mathrm{K}$ generation will also be important. Finally, animal studies demonstrating that $\mathrm{C}-\mathrm{K}$ exerts a chemopreventive effect in colonic tumorigenesis should be undertaken to assess the potential of this agent in future human trials.

\section{Acknowledgements}

This work was supported in part by the NIH/NCCAM grants AT004418, AT005362 and the University of Chicago Digestive Disease Research Core Center (5P30DK042086).

\section{References}

1. Attele AS, Wu JA and Yuan CS: Ginseng pharmacology: multiple constituents and multiple actions. Biochem Pharmacol 58: 1685-1693, 1999.

2. Boon $\mathrm{H}$ and Wong J: Botanical medicine and cancer: a review of the safety and efficacy. Expert Opin Pharmacother 5: 2485-2501, 2004.

3. Jang HI and Shin HM: Wild Panax ginseng (Panax ginseng C.A Meyer) protects against methotrexate-induced cell regression by enhancing the immune response in RAW 264.7 macrophages. Am J Chin Med 38: 949-960, 2010.

4. Lee KD and Huemer RP: Antitumoral activity of Panax ginseng extracts. Jpn J Pharmacol 21: 299-302, 1971.

5. Yun TK and Choi SY: Non-organ specific cancer prevention of ginseng: a prospective study in Korea. Int J Epidemiol 27: 359-364, 1998.

6. Yun TK and Choi SY: Preventive effect of ginseng intake against various human cancers: a case-control study on 1987 pairs. Cancer Epidemiol Biomarkers Prev 4: 401-408, 1995.

7. Wargovich MJ: Colon cancer chemoprevention with ginseng and other botanicals. J Korean Med Sci 16 (Suppl): S81-S86, 2001.

8. Qi LW, Wang CZ and Yuan CS: Ginsenosides from American ginseng: chemical and pharmacological diversity. Phy tochemistry 72: 689-699, 2011

9. Wang CZ, Mehendale SR and Yuan CS: Commonly used antioxidant botanicals: active constituents and their potential role in cardiovascular illness. Am J Chin Med 35: 543-558, 2007.

10. Corbit R, Ebbs S, King ML, et al: The influence of lead and arsenite on the inhibition of human breast cancer MCF-7 cell proliferation by American ginseng root (Panax quinquefolius L.) Life Sci 78: 1336-1340, 2006.
11. Aung HH, Mehendale SR, Wang CZ, et al: Cisplatin's tumoricidal effect on human breast carcinoma MCF-7 cells was not attenuated by American ginseng. Cancer Chemother Pharmacol 59: 369-374, 2007.

12. Xie JT, Du GJ, McEntee E, et al: Effects of triterpenoid glycosides from fresh ginseng berry on SW480 human colorectal cancer cell line. Cancer Res Treat 43: 49-55, 2011.

13. He BC, Gao JL, Luo X, et al: Ginsenoside Rg3 inhibits colorectal tumor growth through the down-regulation of Wnt/ss-catenin signaling. Int J Oncol 38: 437-445, 2011.

14. Tawab MA, Bahr U, Karas M, et al: Degradation of ginsenosides in humans after oral administration. Drug Metab Dispos 31: 1065-1071, 2003.

15. Hasegawa H: Proof of the mysterious efficacy of ginseng: basic and clinical trials: metabolic activation of ginsenoside: deglycosylation by intestinal bacteria and esterification with fatty acid. J Pharmacol Sci 95: 153-157, 2004.

16. Liu HF, Yang JL, Du FF, et al: Absorption and disposition of ginsenosides after oral administration of Panax notoginseng extract to rats. Drug Metab Dispos 37: 2290-2298, 2009.

17. Qi LW, Wang CZ and Yuan CS: Isolation and analysis of ginseng: advances and challenges. Nat Prod Rep 28: 467-495, 2011.

18. Kim DY, Park MW, Yuan HD, et al: Compound K induces apoptosis via CAMK-IV/AMPK pathways in HT-29 colon cancer cells. J Agric Food Chem 57: 10573-10578, 2009.

19. Cho SH, Chung KS, Choi JH, et al: Compound K, a metabolite of ginseng saponin, induces apoptosis via caspase-8-dependent pathway in HL-60 human leukemia cells. BMC Cancer 9: 449, 2009.

20. Whitehead RH, van Eeden PE, Noble MD, et al: Establishment of conditionally immortalized epithelial cell lines from both colon and small intestine of adult $\mathrm{H}-2 \mathrm{~Kb}$-tsA58 transgenic mice. Proc Natl Acad Sci USA 90: 587-591, 1993.

21. Wang CZ, Xie JT, Zhang B, et al: Chemopreventive effects of Panax notoginseng and its major constituents on SW480 human colorectal cancer cells. Int J Oncol 31: 1149-1156, 2007.

22. Chen MJ, Yang PY, Ye YZ, et al: Arsenic trioxide induces apoptosis in uveal melanoma cells through the mitochondrial pathway. Am J Chin Med 38: 1131-1142, 2010

23. Jain AN: Morphological similarity: a 3D molecular similarity method correlated with protein-ligand recognition. J Comput Aided Mol Des 14: 199-213, 2000.

24. Giganti D, Guillemain H, Spadoni JL, et al: Comparative evaluation of 3D virtual ligand screening methods: impact of the molecular alignment on enrichment. J Chem Inf Model 50: 992-1004, 2010.

25. Mann J: Natural products in cancer chemotherapy: past, present and future. Nat Rev Cancer 2: 143-148, 2002.

26. Balunas MJ and Kinghorn AD: Drug discovery from medicinal plants. Life Sci 78: 431-441, 2005.

27. Ernst E: The role of complementary and alternative medicine in cancer. Lancet Oncol 1: 176-180, 2000.

28. Xu Z, Chen X, Zhong Z, et al: Ganoderma lucidum polysaccharides: immunomodulation and potential anti-tumor activities. Am J Chin Med 39: 15-27, 2011.

29. Wang CZ, Aung HH, Ni M, et al: Red American ginseng: ginsenoside constituents and antiproliferative activities of heatprocessed Panax quinquefolius roots. Planta Med 73: 669-674, 2007.

30. Lee J, Lee E, Kim D, et al: Studies on absorption, distribution and metabolism of ginseng in humans after oral administration. J Ethnopharmacol 122: 143-148, 2009.

31. Meunier C, Cai J, Fortin A, et al: Characterization of a major colon cancer susceptibility locus ( $\mathrm{Ccs} 3)$ on mouse chromosome 3 . Oncogene 29: 647-661, 2010.

32. Ravichandran K, Velmurugan B, Gu M, et al: Inhibitory effect of silibinin against azoxymethane-induced colon tumorigenesis in A/J mice. Clin Cancer Res 16: 4595-4606, 2010. 